\title{
O LABORATÓRIO DE APRENDIZAGEM INTEGRADA COMO COMPONENTE CURRICULAR NOS CURSOS DE ENGENHARIA.
}

DOI: 10.37702/2175-957X.COBENGE.2021.3631

Rodrigo Boeing Althof - eng.rodrigoalthoff@gmail.com

Instituto Federal Catarinense IFC

Rua Hercílio Fides Zimmermann 15

89116-650 - Gaspar - SC

tiago giuriatti - tiago.giuriatti@ifc.edu.br

UFSC

Rua Franz Volles 1636

89066-100 - Blumenau - SC

João Bosco da Mota Alves - jbosco@inf.ufsc.br

Universidade Federal de Santa Catarina

Rua Pedro João Pereira 150

88905-120 - Araranguá - SC

Resumo: A formação dos estudantes de Engenharia deve também fazer uso de metodologias inovadoras que ultrapassam o treinamento puramente técnico e tradicional. Nesta acepção, o presente artigo tem por objetivo avaliar as contribuições das disciplinas de Laboratório de Aprendizagem Integrada (LAI) nos cursos de graduação em engenharia no Centro Universitário Sociesc de Blumenau, e quais as competências complementares necessárias aos estudantes de engenharia na formação de um sujeito ético, crítico, reflexivo, transformador e humanizado. $O$ estudo busca a reflexão sobre as competências apontadas como essenciais para o século XXI (soft skills), desde a conceituação destas competências até sua relevância no processo formativo de professores. A utilização das metodologias ativas, como o LAl e uso das tecnologias podem ser um componente tático de inovação das práticas pedagógicas, direcionando a formação da identidade dos alunos de modo a desenvolver as habilidades e competências necessárias para os desafios sociais e profissionais aos quais estarão expostos.

Palavras-chave: Ensino de engenharia. Soft Skills. Metodologias ativas. 


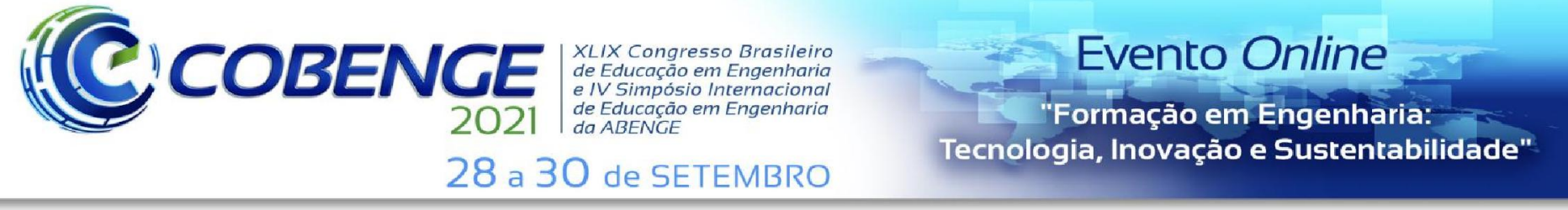

Faria et al. (2017, p. 6) destacam que "As competências de que os alunos necessitam para o século XXI não são novas. O pensamento crítico e a resolução de problemas, por exemplo, são dimensões há muito associadas ao desempenho acadêmico e aos processos de ensino e aprendizagem".

Essa lacuna aumentará significativamente, a menos que seja intencional, bem direcionada. As facilidades são colocadas em prática no ensino de engenharia para promover especificamente as habilidades do século XXI. Os resultados de aprendizagem, o desenho do currículo, as práticas de sala de aula, as tarefas de aprendizagem e avaliação têm que ser coerentemente elaboradas e implementadas de modo a facilitar uma experiência flexível, personalizada e significativa para o estudante.

As metodologias ativas vêm sendo amplamente difundidas, e têm se apresentado como eficazes, por serem estratégias que minimizam ou solucionam alguns dos problemas encontrados no ambiente escolar. Entre suas potencialidades estão a de impulsionar o envolvimento dos alunos por meio de atividades lúdicas, como o uso de jogos, resolução de desafios, e partir de situações vivenciadas por eles para tratar de temas como cidade ou meio ambiente.

O mercado de trabalho tem exigido dos novos profissionais além destes conhecimentos, outras habilidades e competências. Nesta acepção, o presente artigo tem por objetivo avaliar as contribuições das disciplinas de Laboratório de Aprendizagem Integrada (LAI), e quais as competências complementares e necessárias ao estudante de graduação em Engenharia, bem como estas competências são desenvolvidas durante as práticas de ensino aprendizagem das disciplinas LAl nos cursos de graduação em Engenharia no Centro Universitário Sociesc de Blumenau.

\section{COMPETÊNCIAS PARA O SÉCULO XXI}

As competências possibilitam aos estudantes a melhoria de suas interações com seus pares e com o mundo que os rodeia. Tais competências são caraterizadas por não serem exclusivas para determinada função, sendo úteis em qualquer área profissional e mais valiosas ainda para a vida pessoal dos estudantes.

Como tendência também em outras áreas, algumas organizações já estão preferindo estudantes com menos conhecimentos técnicos, porém com mais responsabilidade, mais assiduidade, disponibilidade para aprender e mais comunicativos, uma vez que as competências técnicas podem ser adquiridas nas escolas e faculdades e aprimoradas no próprio ambiente da empresa.

Os conceitos de competência são apresentados em conformidade com alguns autores para que o entendimento do contexto deste trabalho e as competências dos estudantes de engenharia sejam mais bem assimilados.

Mas afinal, o que são competências?

O dicionário Aurélio de língua portuguesa, descreve o termo competência como sendo a "Capacidade decorrente do profundo conhecimento que alguém tem sobre um assunto". Pode-se afirmar que a competência está descrita como a capacidade de usar a inteligência e os recursos mentais para a realização de determinada tarefa com a maior eficiência.

Para Mello (2014, p.8):

Aprender a aprender, saber lidar com a informação cada vez mais disponível, aplicar conhecimentos para resolver problemas, ter autonomia para tomar decisões, ser proativo para identificar os dados de uma situação 


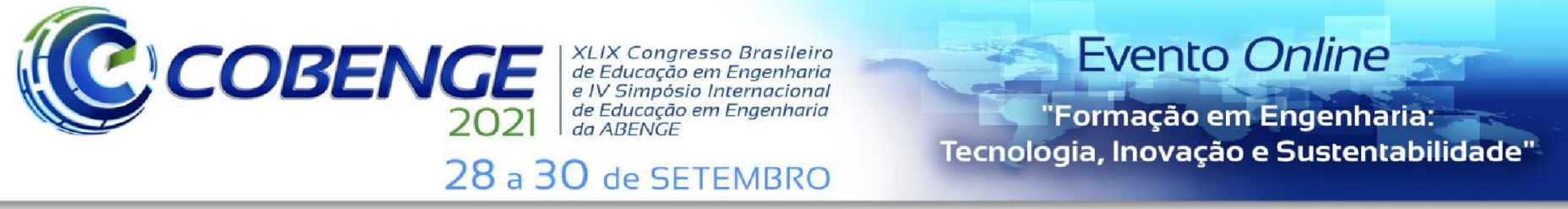

e buscar soluções tornam-se objetivos mais valiosos do que o conhecimento desinteressado e erudito da escola do passado. Os resultados das aprendizagens precisam se expressar e se apresentar como a possibilidade de operar o conhecimento em situações que requerem aplicá-lo para tomar decisões pertinentes.

Corroborando com este conceito:

[...] define-se competência como sendo a capacidade de agir eficazmente em um determinado tipo de situação, apoiando-se em conhecimentos, mas sem se limitar a eles. Para enfrentar uma determinada situação, colocam-se geralmente em ação vários recursos cognitivos, uma vez que quase toda ação mobiliza conhecimentos, algumas vezes elementares e esparsos, outras vezes complexos e organizados em rede (BRASIL, 2008, p.18).

Perrenoud (1999), explica competência como sendo "a capacidade de agir eficazmente em um determinado tipo de situação, apoiando-se em conhecimentos, mas sem se limitar a eles".

Para Mascarenhas (2008, p. 184), quando se define competência, é primordial que se observe a unicidade que caracteriza cada evento e como resultado o exercício das competências.

Competências podem ser descritas como sendo um conjunto de três elementos:

- Conhecimento: Ou Saber;

- Habilidades: Saber fazer e;

- Atitude: Saber fazer acontecer.

O conjunto destes três elementos forma a competência, isto é, as características que a pessoa aprendeu ou irá aprender.

Com intuito de ajudar os estudantes a desenvolverem este novo perfil profissional muitas instituições buscam enriquecer suas propostas de formação baseadas nos quatro pilares da Educação, que segundo o relatório da Comissão Internacional sobre a Educação para o século 21, elaborado para a UNESCO, que destaca os quatro pilares:

a) Aprender a conhecer: Neste pilar o destaque fica no desenvolvimento do potencial cognitivo do estudante e na sua capacidade de aprender a aprender;

b) Aprender a fazer: Prioriza a criação de situações onde os estudantes adquirem competências e habilidades para resolverem problemas cotidianos, aplicando o uso de seus conhecimentos obtidos em suas experiências cotidianas;

c) Aprender a conviver: Neste sentido procura-se desenvolver a empatia dos estudantes, a compreensão de que se vive num mundo de diversidades, sejam elas de quaisquer formas: cultural, étnica, racial, social etc.;

d) Aprender a ser: Trabalha-se a atitude dos estudantes, onde suas ações devem ser pautadas no protagonismo ao mesmo tempo em que se fortalece suas potencialidades: o raciocínio e principalmente o autoconhecimento.

Tomando por base estes pilares, Chu et. al (2012, p. 21) esquematizaram as habilidades necessárias para que os estudantes enfrentem os desafios impostos pelo século 21, dividindo em três grupos, conforme visto no Quadro 1. 
Quadro 1- Competências relacionadas a cada grupo de habilidades para o Século 21

\begin{tabular}{|c|c|c|}
\hline Aprendizagem e Inovação & Letramentos Digitais & Vida e Carreira \\
\hline Pensamento Crítico & Letramento informacional & Flexibilidade \\
Resolução de problemas & Letramento midiático & Adaptação \\
Comunicação & Letramento tecnológico & Autonomia \\
Colaboração & & Interação social \\
Criatividade & & Interação cross-cultural \\
Inovação & Produtividade \\
& & Liderança \\
& & Responsabilidade \\
& Accountability \\
\hline
\end{tabular}

Fonte: CHU et al., 2012, p. 21.

O aspecto técnico não deve ser o único elemento a caracterizar o perfil do engenheiro, que deve ser complementado pelo aspecto comportamental, humano, tecnológico, e por seus conhecimentos, competências e atitudes. As diferentes realidades e os conflitos inerentes ao mundo dos profissionais de engenharia demandam a necessidade do desenvolvimento e uso de diversas habilidades comportamentais para alcançar os objetivos e atender às partes interessadas.

Entende-se por competência (ou skills) o nível de eficiência de um indivíduo na execução de uma determinada capacidade adquirida, ou seja, o quanto está qualificado para realizar um algum trabalho. Competência é "um saber agir responsável e reconhecido, que implica mobilizar, integrar, transferir conhecimentos, recursos e habilidades, que agreguem valor econômico à organização e valor social ao indivíduo" (Fleury \& Fleury, 2001, p. 188).

Enquanto hard skills são competências técnicas e conhecimento de domínio, soft skills são uma combinação de habilidades pessoais, habilidades interpessoais, habilidades de comunicação e inteligência emocional, dentre elas a autoconsciência, autogestão, consciência social e gestão de relacionamento (FME, 2014), que ajudam a garantir a clareza nas mensagens e a construção de confiança e relacionamentos.

\subsection{Desafios no ensino de engenharia}

Destarte que apenas o conhecimento técnico não é mais o suficiente para que os estudantes sejam formados e transformados em bons profissionais. Eles precisam deter o autoconhecimento, a colaboração e principalmente a comunicação, dentre outras competências. As instituições que dispuserem aos seus estudantes estas competências desenvolverão profissionais mais capazes de enfrentar os novos desafios do século.

As diretrizes curriculares dos cursos de graduação estabelecidas anteriormente pelo parecer CNE/CES n 776 de 3 de dezembro de 1997 tinham uma visão muito tecnicista. Vale ressaltar que antes da lei $n^{\circ} 9.394$ de 20 de dezembro de 1996, eram fixados currículos mínimos nos cursos de graduação com grande rigidez curricular (BRASIL, 1997). Como exemplo a Resolução CNE/CES 11/2002:

O Engenheiro é um profissional de formação generalista, que atua na concepção, planejamento, projeto, construção, operação e manutenção de edificações e de infraestruturas. Suas atividades incluem: supervisão, coordenação e orientação técnicas; estudo, planejamento, projeto e especificação; estudo de viabilidade técnico-econômica; assistência, assessoria e consultoria; direção, execução e fiscalização de obra e serviço técnico; vistoria, perícia, avaliação, arbitramento, laudo e parecer técnico. Pode desempenhar cargos e funções técnicas, elaborar orçamentos e 
cuidar de padronização, mensuração e controle de qualidade. Pode coordenar equipes de instalação, montagem, operação, reparo e manutenção. Executa desenho técnico e se responsabilizar por análise, experimentação, ensaio, divulgação e produção técnica especializada. Coordena e supervisiona equipes de trabalho, realiza estudos de viabilidade técnico-econômica, executa e fiscaliza obras e serviços técnicos; e efetua vistorias, perícias e avaliações, emitindo laudos e pareceres. Em suas atividades, considera a ética, a segurança, a legislação e os impactos ambientais.

A mesma resolução em seu artigo $4^{\circ}$, indica que a formação do engenheiro tem por objetivo dota o profissional dos conhecimentos requeridos para o exercício das seguintes competências e habilidades gerais:

i. Aplicar conhecimentos matemáticos, científicos, tecnológicos e instrumentais em engenharia;

ii. projetar e conduzir experimentos e interpretar resultados;

iii. conceber, projetar e analisar sistemas, produtos e processos;

iv. planejar, supervisionar, elaborar e coordenar projetos e serviços de engenharia;

v. identificar, formular e resolver problemas de engenharia;

vi. desenvolver e/ou utilizar novas ferramentas e técnicas;

vii. supervisionar a operação e a manutenção de sistemas;

viii. avaliar criticamente a operação e a manutenção de sistemas;

ix. comunicar-se eficientemente nas formas escrita, oral e gráfica;

$\mathrm{X}$. atuar em equipes multidisciplinares;

xi. compreender e aplicar a ética e responsabilidade profissional;

xii. avaliar o impacto das atividades da engenharia no contexto social e ambiental;

xiii. avaliar a viabilidade econômica de projetos de engenharia;

xiv. assumir a postura de permanente busca de atualização profissional.

Em 2019, houve a aprovação da Resolução CES/CNE/MEC n. ${ }^{\circ}$ 2, de 24 de abril de 2019 que instituiu as novas Diretrizes Curriculares Nacionais para os Cursos de Graduação em Engenharia (DCN's), e que recomendam a inclusão das atividades acadêmicas complementares nos currículos dos cursos de Engenharia de forma alinhada ao perfil do egresso e às competências estabelecidas (BRASIL, 2019).

A partir desta perspectiva muitas instituições promoveram atualizações em suas matrizes curriculares e a inserção de elementos das chamadas Soft Skills.

De acordo com a nova DCN em seu artigo $3^{\circ}$, o perfil do egresso do curso de graduação em Engenharia deve compreender, entre outras, as seguintes características:

i. ter visão holística e humanista, ser crítico, reflexivo, criativo, cooperativo e ético e com forte formação técnica;

ii. estar apto a pesquisar, desenvolver, adaptar e utilizar novas tecnologias, com atuação inovadora e empreendedora;

iii. ser capaz de reconhecer as necessidades dos usuários, formular, analisar e resolver, de forma criativa, os problemas de Engenharia;

iv. adotar perspectivas multidisciplinares e transdisciplinares em sua prática;

v. considerar os aspectos globais, políticos, econômicos, sociais, ambientais, culturais e de segurança e saúde no trabalho;

vi. atuar com isenção e comprometimento com a responsabilidade social e com o desenvolvimento sustentável. 
E o engenheiro deve ter a habilidade de projetar, gerenciar e executar ações das mais variadas proporções, o que chamamos de habilidades técnicas (hard skills), mas sem nunca se esquecer da sua responsabilidade em deixar um legado positivo no entorno de sua obra, projeto ou serviço, seja para as pessoas ou para a paisagem, e neste contexto a importância de desenvolver as habilidades gerenciais e habilidades comportamentais (soft skills).

Possíveis falhas no aprendizado das disciplinas exatas em nosso país, na educação de base, impedem que muitos entrem no ramo das engenharias, ou faz com que alunos mal preparados encontrem uma enorme dificuldade logo no início do curso, quando encaram as temidas cadeiras iniciais de cálculos e físicas, com níveis de dificuldade nem comparados ao ensino médio.

Nos cursos de engenharia é comum prevalecer a chamada transposição do conhecimento, ou seja, ensinar conforme foi aprendido; contudo, nos casos em que a transmissão do conhecimento foi bem-sucedida, deve existir algo que possa ser identificado, estudado e aprimorado, proporcionando um ciclo virtuoso. O referencial teórico educacional é uma das chaves de acesso para este ciclo virtuoso, juntamente com outras estratégias pedagógicas, transformando o ato de ensinar em um procedimento consciente e intencional.

Entretanto, tais atividades apresentam posição complementar à formação estudantil, e mesmo considerando-se que suscitam a curiosidade dos alunos na busca do conhecimento e da aplicação dos conceitos de seus cursos à atividade em si, não conseguem sustentar, de forma completa e conclusiva, o conjunto das competências que são necessárias para sua formação.

O ensino técnico da engenharia está nas mãos de engenheiros, todavia, muitos destes profissionais não possuem formação para exercer a atividade de docente, desconhecendo as principais teorias e técnicas de aprendizagem e metodologias ativas. Saber diferenciar comportamentalismo, cognitivismo e humanismo e entender as contribuições de tais linhas filosóficas no processo educacional, proporciona uma melhor compreensão de como ocorrem os processos de ensino e aprendizagem (MOREIRA, 1999).

Dominar os conteúdos de uma disciplina é fator determinante para o desempenho da atividade do professor; todavia, isto não é suficiente. Nesse momento, vale a pena fazer o seguinte exercício: colocar-se no lugar do aluno, voltar no tempo e, das próprias lembranças, resgatar aquela aula de elevado grau de dificuldade que era ensinada com clareza, coerência e, principalmente, de forma cativante por este ou aquele professor certamente ali existia algo que fazia a diferença nos processos de ensino e aprendizagem.

\subsection{O laboratório de aprendizagem integrada - LAI}

No Brasil, tem-se observado que as Instituições de Ensino Superior, vêm formando muitos profissionais altamente qualificados tecnicamente, mas as organizações estão apontando para a necessidade do desenvolvimento de novas competências, as chamadas soft skills, ou competências socioemocionais. A falta destas competências tem sido considerada como principal fator para a não inserção dos recém-formados no mercado de trabalho.

O Laboratório de Aprendizagem Integrada (LAI) pode ser definido como sendo um componente tático contemplado de inovação das práticas pedagógicas, com objetivo de direcionar a formação da identidade dos alunos de modo amplo, de modo a desenvolver as 


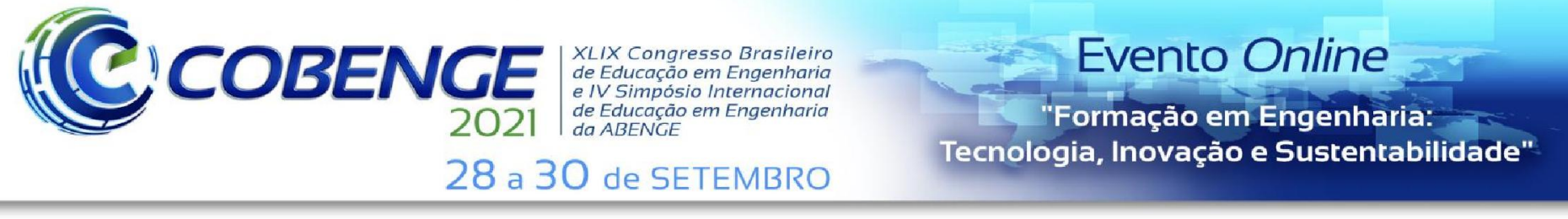

habilidades e competências necessárias para os desafios sociais e profissionais aos quais estarão expostos.

\subsection{Procedimentos metodológicos}

O currículo adotado foi pensado como forma de propiciar a experimentação das ideias, integrado e organizado para que a teoria passe a fazer parte da experiência vivida.

É essencialmente pautado por leituras do contexto no qual se produz e estruturado de modo a contribuir para o desenvolvimento dos alunos em múltiplas perspectivas. Para garantir a formação integral dos discentes, promove um ecossistema de aprendizagem interdisciplinar, calcado na articulação entre ensino, trabalho e comunidade.

Diante destas premissas, realizou-se uma pesquisa bibliográfica e de abordagem qualitativa, verificando o disposto nas diretrizes curriculares dos cursos de engenharia para o ensino de engenharia frente aos desafios para o desenvolvimento das competências comuns a qualquer área profissional e que possam complementar a formação dos estudantes.

Mesmo que em grande parte das diretrizes curriculares destes cursos, além das habilidades específicas, as próprias competências e habilidades gerais que podem ser oriundos de outras áreas do conhecimento para os Engenheiros, não se exclui a eminente natureza específica técnica de área.

Porém, nas próprias DCN's de curso, mesmo que não se evidencie a formação complementar diretamente, se permitem a sua aplicação. E assim, de modo complementar tem-se a possibilidade de inserção das metodologias ativas e de se trabalhar conjuntamente as competências e às constantes transformações estruturais, tecnológicas e dos sujeitos envolvidos nas práticas pedagógicas significativas e que realmente proporcionem processos de ensino e de aprendizagem.

Nestas premissas, o Laboratório de Aprendizagem Integrada (LAI) é o componente curricular do Centro Universitário SOCIESC de Blumenau que, no âmbito da dimensão Projeto de Vida, define-se como a face prática e operacional das experiências de aprendizagem.

O conceito de laboratório, comumente associado à noção de espaço físico para estudos científicos e técnicos, expande-se para designar todos e quaisquer espaços e tempos, virtuais ou reais, dedicados à investigação, à experimentação e à vivência colaborativa em torno da produção do conhecimento.

Com o LAl aplicamos novas e diferenciadas oportunidades didáticas de interação e de mediação das aprendizagens, tendo deste modo os seguintes critérios:

- Experimentação e integração dos conhecimentos teóricos e práticos no desenvolvimento de projetos como fonte de aprendizagem significativa e do crescimento individual e coletivo;

- Estudo e debate dos principais temas contemporâneos de formação geral, articulados às bases teóricas da formação específica;

- Reflexão sobre os principais desafios da sociedade contemporânea multicultural e sobre os princípios elementares do exercício pleno da cidadania;

- Exercício pleno da liberdade de pensamento, de sentimento e de imaginação, de forma lógica, crítica, analítica e criativa, em prol do desenvolvimento do talento e das habilidades pessoais em potencial;

- Promoção de aprofundamento e de avaliação crítica das capacidades individuais, na perspectiva de ampliar competências para planejar e promover mudanças significativas na vida pessoal, profissional e social. 
Diante destes critérios, o papel do professor passa a ser o de mediador-mentor, devendo contribuir para o desenvolvimento pessoal, profissional e cidadão do estudante. 0 professor deve propor atividades e projetos, elaborar ou disponibilizar materiais de consulta, sugerir leituras, criar debates e oficinas, discutir com os alunos seus anseios e dificuldades e avaliar conjuntamente o trabalho realizado.

Como elemento integrante, estruturante e transversal da matriz curricular, o LAI materializa-se como duas disciplinas que o aluno tem a oportunidade de vivenciar no ciclo inicial de aprendizagem:

Disciplina 1: LAI - Identidade, Criatividade e Resolução de Problemas.

Disciplina 2: LAI - Comunicação, Diversidade e Pensamento Crítico.

O LAl conta ainda com o suporte de uma plataforma virtual multimídia, cujos conteúdos estimulam o desenvolvimento de competências socioemocionais (soft skills), consideradas fundamentais tanto para a boa inserção no mundo do trabalho quanto para o desenvolvimento pessoal e cidadão do aluno.

A esta plataforma denominada de Laboratório de Aprendizagem Integrada Virtual (LAIV), se tem como principal propósito intensificar a reflexão sobre os conteúdos norteadores nos encontros presenciais. É um ambiente on-line gamificado, que dispõe de objetos de aprendizagem, como jogos, textos, vídeos e quiz. Proporciona, assim, uma experiência formativa personalizada e com elementos de motivação que buscam garantir a permanência e a participação dos estudantes na plataforma.

A possibilidade de articulação entre os conhecimentos obtidos no ambiente virtual e as experiências propostas pelo professor na sala de aula fazem dessa ferramenta digital um insumo relevante para o processo educativo. Além de contribuir e enriquecer as práticas presenciais, o LAIV é um estímulo ao desenvolvimento da autonomia e da autorregulação dos estudantes, que passam a ser protagonistas de sua própria aprendizagem, devendo estabelecer um ritmo e um planejamento individual para acessar e consultar os materiais e os exercícios disponíveis na plataforma.

Ao entrar no LAIV, o aluno encontra trilhas de desenvolvimento de competências previstas no escopo do Projeto de Vida. Cada etapa (estação) dos itinerários formativos (linhas de metrô) está relacionada a uma ou mais áreas de competências e é voltada para o conjunto de habilidades que se pretende desenvolver.

Tanto o LAI quanto o LAIV, são unidades curriculares cursadas no ciclo inicial do curso, e desempenham a função de preparar e auxiliar os estudantes no desenvolvimento de um estudo autônomo e motivado por escolhas, algo que farão ao longo de todo o percurso formativo. Proporcionam, também, uma ambiência inicial dos alunos à incorporação das tecnologias digitais ao estudo, solidificando neles a cultura de emprego das ferramentas digitais educacionais como insumo indispensável e natural ao processo educativo.

\section{RESULTADOS E DISCUSSÕES}

Existem muitas formas criativas para implementar novas metodologias e a formação por base nas competências. Apresentamos o modelo do Laboratório de Aprendizagem Integrada, o LAI, que permite o pensamento crítico e a resolução de problemas, como um componente tático contemplado de inovação das práticas pedagógicas, com objetivo de direcionar a formação da identidade dos alunos de modo amplo, de modo a desenvolver as habilidades e competências necessárias para os desafios sociais e profissionais aos quais estarão expostos. 


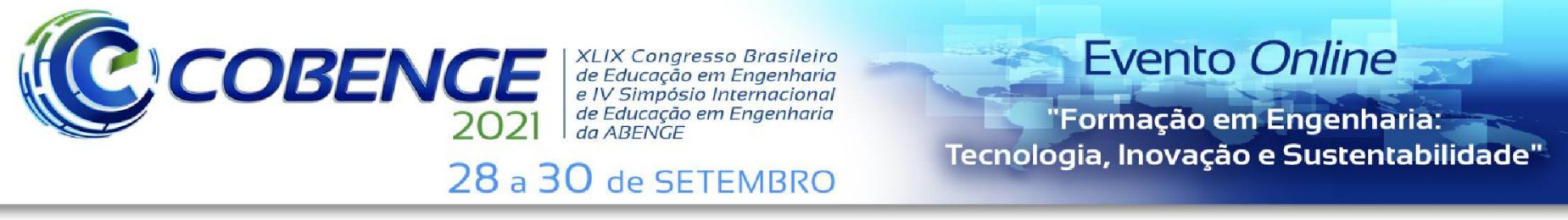

apontando para a necessidade do desenvolvimento de novas competências, as chamadas soft skills, ou competências socioemocionais. A falta destas competências tem sido considerada como principal fator para a não inserção dos recém-formados no mercado de trabalho.

O Laboratório de Aprendizagem Integrada (LAI) pode ser definido como sendo um componente tático contemplado de inovação das práticas pedagógicas, com objetivo de direcionar a formação da identidade dos alunos de modo amplo, de modo a desenvolver as habilidades e competências necessárias para os desafios sociais e profissionais aos quais estarão expostos.

Temas como a identidade, criatividade, resolução de problemas, comunicação, diversidade e pensamento crítico são necessários aos estudantes na formação de um sujeito ético, crítico, reflexivo, transformador e humanizado.

Os componentes curriculares de aprendizagem propostos mobilizam discentes, docentes, coordenadores e diretores em ações que potencializam o debate interdisciplinar para além das disciplinas, envolvendo os alunos em questões e problemas que ultrapassam os muros universitários. Diferentes eixos de formação que perpassam o currículo convocam a problematizar a realidade, em lugar de tomá-la simplesmente como parâmetro de ensino ou de reproduzi-la acriticamente.

Assim, podemos concluir que este é um elemento estruturante e estratégico de inovação das práticas pedagógicas, e que enriquece as experiências de aprendizagem e conecta-as com a vida, ampliando e flexibilizando tempos e espaços.

Um novo trabalho pode avaliar os resultados da possível integração de turmas diferentes em estágios mais avançados dos respectivos cursos, de forma a manter uma matriz curricular que atenda os preceitos legais, mas conectada a realidade e aos desafios do mercado, "uma matriz curricular viva", que permita aos estudantes expandir suas habilidades e que possam as coloca em prática constante.

\section{Agradecimentos}

Agradecemos ao Centro Universitário Sociesc de Blumenau e aos professores das disciplinas de Laboratório de Aprendizagem Integrada - LAI.

\section{REFERÊNCIAS}

BRASIL. Lei $n^{\circ}$ 9.394, de 20 de dezembro de 1996. Estabelece as diretrizes e bases da educação nacional. Diário Oficial da União: seção 1, Brasília, DF, 23 dez. 1996.

BRASIL (Ministério da Educação). Resolução CES/CNE/MEC n. ${ }^{2}$, de 24 de abril de 2019. Dispõe sobre diretrizes curriculares nacionais do curso de graduação em engenharia. Disponível em: <https://www.in.gov.br/web/dou/-/resoluÇÃo-nº-2-de-24-de-abril-de-201985344528>. Acesso em: 1 de mar. de 2021.

CHU, Sam; TAVARES, Nicole; CHU, Donna; HO, Shun Yee; CHOW, Ken; SIU, Felix; WONG, Mona. Developing upper primary students' 21st century skills: inquiry learning through collaborative teaching and web 2.0 technology. Hong Kong: Centre for Information Technology in Education, Faculty of Education, The University of Hong Kong, 2012.

CONSELHO NACIONAL DE EDUCAÇÃO - CNE. Resolução CNE/CES 11/2002. Diário Oficial da União, Brasília, 9 de abril de 2002. Seção 1, p. 32. 
CONFEDERAÇÃO NACIONAL DA INDÚSTRIA - CNI. Fortalecimento das engenharias/ Confederação Nacional da Indústria. Brasília: CNI, 2015.

FARIA, Ercília et al. Perfil do aluno - competências para o século XXI. Lisboa: Conselho Nacional de Educação (CNE), 2017. 107 p.

FLEURY, M. T. L., \& FLEURY, A. (2001). Construindo o Conceito de Competência. In: RAC, Edição Especial, 183-196.

FREE MANAGEMENT EBOOKS - FME (2014). Project stakeholder management: project skills. FME: project skills. FME. Disponivel em: <http://www.free-managementebooks.com/dldebk-pdf/fme-projectstakeholder. pdf>. Acesso em: 28 Jan 2021.

MASCARENHAS; A. O. Gestão estratégica de pessoas: evolução, teoria e crítica. São Paulo: Cengage Learning, 2008.

MOREIRA; M. A. Teorias de aprendizagem. São Paulo: EPU, 1999. 195 p.

PERRENOUD; P. Construir as competências desde a escola. Trad. Bruno Charles Magne. Porto Alegre: Artes Médicas Sul, 1999.

\title{
THE INTEGRATED LEARNING LABORATORY AS A CURRICULAR COMPONENT IN ENGINEERING COURSES
}

\begin{abstract}
The training of engineering students must also make use of innovative methodologies that go beyond purely technical and traditional training. In this sense, this article aims to assess the contributions of the Integrated Learning Laboratory (LAI) disciplines and what complementary skills are required for engineering students in the formation of an ethical, critical, reflective, transformative and humanized subject. The study seeks to reflect on the competences identified as essential for the 21st century, from the conceptualization of these competences to their relevance in the teacher training process. The use of active methodologies, such as LAI and use of technologies can be a tactical component of innovation in pedagogical practices, directing the formation of students' identity in order to develop the skills and competences necessary for the social and professional challenges to which they will be exposed
\end{abstract}

Keywords: Engineering Teaching. Soft Skills. Active methodologies. 